\title{
Deleuze, Bene e o projecto de um teatro menor
}

\author{
Inês Lago
}

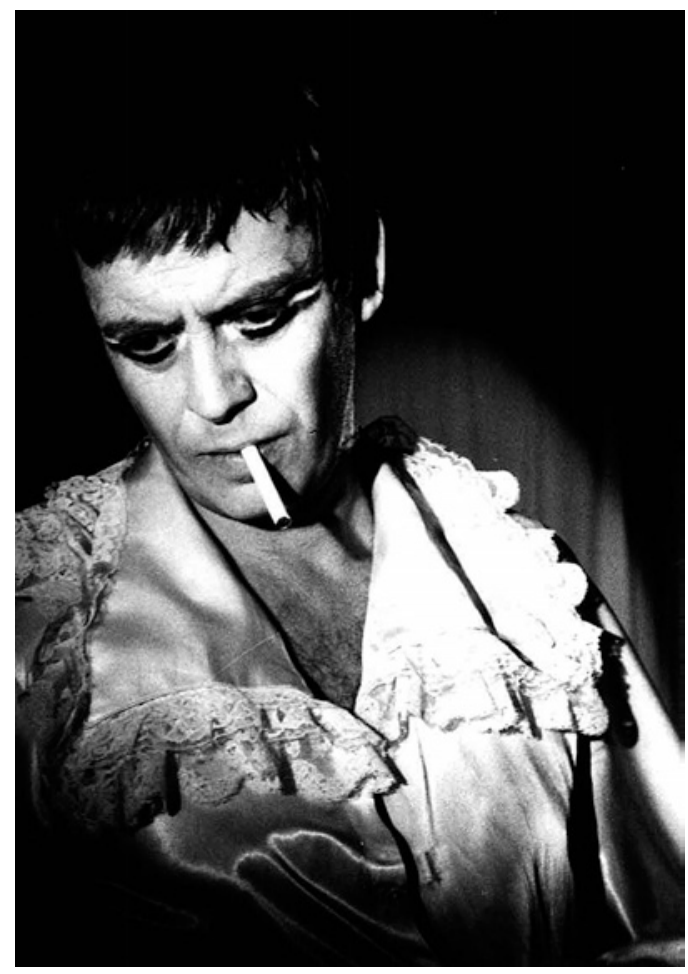

A ligação entre Gilles Deleuze e Carmelo Bene, cujo exemplo mais concreto encontramos em Superpositions, baseouse essencialmente na procura de um método, de uma via de construção que conseguisse escapar à doxa, ao domínio da pura recognição. A verdade é que Deleuze sempre se muniu de conceitos teatrais para trabalhar o seu pensamento, como Bene trabalhou sempre muito próximo da filosofia na construção da sua linguagem cénica. Tanto Deleuze como Bene procuram o novo, a diferença, mas sem com isso recusarem por absoluto a totalidade dos apriorismos: é falaciosa a ideia de tabula rasa, não se consegue criar a partir do nada, não interessa o zero. $\mathrm{Ou}$, como surge em Rizoma: "não se podem estabelecer cortes radicais entre os regimes de signos e os seus objectos" (Deleuze/Guattari 2004:16). 0 que interessa é desenvolver mecanismos que permitam alcançar novas velocidades e produzir novos agenciamentos. Bene, ao trabalhar a partir dos clássicos, produz a diferença pela repetição, e a repetição pela diferença. Agindo por subtracção, pela amputação de certos elementos, Bene produz sempre um novo acontecimento. E embora este acontecimento possa manter ligação a um certo sentido de passado, de presente ou de futuro (a uma representatividade, portanto), produz sempre uma sintese que fornece à repetição o novo. Entendermos hoje que aquilo que foi o projecto de um "teatro menor" pode lançar-nos algumas luzes sobre os caminhos actuais das artes performativas, na medida em que nos parece que, mesmo de maneira indirecta, as coordenadas lançadas por Bene e Deleuze são hoje paradigmáticas nas formulações estéticas do panorama performativo nacional.

0 filósofo e o artista intersectam-se no projecto de um teatro filosófico: servem-se um ao outro, e um do outro. Deleuze vê na obra de Bene a materialização, se não do método, pelo menos do esforço filosófico que perpassa toda a sua teoria; e Bene descobre em Deleuze uma voz de força em que pode apoiar a sua própria procura artística. Ambos influenciados por Nietzsche e pelo conceito de eterno retorno, assumem o problema da possibilidade (ou da impossibilidade) de produção do novo como a urgência mais vital de todas. Escapar de vez ao julgamento de deus, ao deus da forma, da estrutura, escapar à representação, construir um plano onde o Übermensch possa viver livremente. Esse plano, não mais transcendente, mas imanente, é um plano aberto mas caótico, onde intersecções se dobram e afundam: é o plano da imaginação:

A verdadeira repetição é a da imaginação. Entre uma repetição que não pára de se desfazer em si e uma repetição que se desdobra e se conserva em nós no espaço da representação, houve uma diferença, que é o para-si da repetição, o imaginário. (Deleuze 2000: 149)

É no sentido em que "a diferença habita a repetição" que o imaginário de Carmelo Bene parte sempre do já instalado, do pré-existente: é aí que poderemos
Superpositions, Carmelo Bene e Gilles Deleuze, 1979 (Carmelo Bene).

Inês Lago

é licenciada em Antropologia e mestre em Filosofia Estética pela FCSH-UNL. Como doutoranda em Estudos de Teatro na FLUL,

continua a investigação acerca da crise da representação iniciada no mestrado.

Frequentou o curso de interpretação da Escol Superior de Teatro e Cinema entre 2005 e 2007, e continua desenvolver trabalho enquanto criadora $\mathrm{e}$ actriz n'A Palavra Que Resta (que fundou em 2008) e na Organização. 
eventualmente construir o novo, o diferente: "Transvasar à repetição algo novo, transvasar-Ihe a diferença, é este o papel da imaginação ou do espirito que contempla nos seus estados múltiplos e fragmentados" (Ibid.) 0 pensamento da diferença é o pensamento da criação, não do reconhecimento. $\dot{E}_{1}$ acima de tudo, um acontecimento. Bene recusa a história, o historicismo, os elementos de poder, porque estes representam, estruturam: são reconhecimentos e não acontecimentos. Utiliza a subtracção para desenvolver "virtualidades inesperadas", para potencializar o acontecimento. Os elementos de poder são o reconhecimento, a representação, o obstáculo à formulação do novo: eliminando-os, estaremos a desvelar potencialidades que o plano geral, estruturado, nos não deixava descobrir. Mais uma vez, não se trata de recusar o que quer que seja, mas sim de se mudar, não o ponto, mas o plano de visão: para subtrair, para potenciar o acontecimento. Bene usa o exemplo de uma folha que vai aproximando do nariz: abstraindo cada vez mais o plano geral, afastando-se das margens até ver apenas uma parte reduzida e desfocada (anamorfose). Já não há história, não há confronto, não há mapa. Está-se então pronto para a criação esquizofrénica, para estabelecer um teatromáquina, um teatro sem órgãos, rizomático: "A esquizoanálise recusa qualquer ideia de fatalidade decalcada qualquer que seja o nome que se Ihe dê, divina, anagógica, histórica, económica, estrutural, hereditária ou sintagmática." (Deleuze/Guattari 2004:30)

Há que fazer divergir as faculdades, em vez de as fazer convergir, seleccionar os casos singulares, esquecendo o plano geral em que se movimentam primariamente. Se tomarmos o termo remember, este desmembrar de que falamos prende-se precisamente ao esquecimento: há que amputar os elementos, os membros que estabelecem confrontos, hierarquias, planos de consistência:

Vai-se então cortar/esconder ou amputar a história, porque a História é o carimbo temporal do Tempo. Vai-se cortar a estrutura, porque ela é o marcador sincrónico, o conjunto das relações entre invariantes. Vai-se subtrair as constantes, os elementos estáveis ou estabilizados, porque eles pertencem ao uso maior. Vai-se amputar o texto, porque o texto é como a dominação da lingua sobre a palavra, e testemunho de uma invariância ou de uma homogeneidade. Subtrai-se o diálogo, porque o diálogo transmite à palavra os elementos de poder, e fálos circular: é a sua vez de falar, nessas condições codificadas. (Deleuze 1979:103)

0 que nos refere aqui Deleuze acerca do teatro de Carmelo Bene será válido tanto para a experiência teatral como para a experiência filosófica. Como diz Deleuze em Mille Plateaux, há que "substituir a anamnese pelo esquecimento, e a interpretação pela experimentação". Não mais um remember, mas um dismember, não mais uma convergência para a totalidade, mas um método de fragmentação, de multiplicação, que sirva para erguer novos "blocos de sensações". Bene escolhe dar um tratamento menor aos autores maiores, de maneira a extrair novas possibilidades de devir: ao amputar Romeu, desenvolve Mercutio, ao manter apenas Ricardo III e os elementos femininos, desenvolve novas potencialidades (obs)cénicas, poéticas, imagéticas, antropológicas e filosóficas. Permitir novos agenciamentos ao abolir uma estruturação predefinida faz parte daquilo a que Deleuze se refere como a operação crítica completa, que deve em primeiro lugar "eliminar os elementos estáveis e de seguida colocar tudo em variação contínua, e depois transpor em menor" (Ibid.: 106). Os operadores devem, assim, responder à ideia de intervalo minimo, trabalhar dentro desses limites pois, alargando as fronteiras, cair-se-á de novo no domínio do reconhecivel, do representável, da doxa. A ideia de objectos parciais prende-se à definição de menor. Da menoração farão parte os fragmentos, os isolamentos das partes estruturalmente unitárias. Um Shakespeare transformado em mil potências, em infinitos devires.

Estes fragmentos anamórficos devem (de)formar-se "segundo uma linha de variação contínua", devem ser, como diria Michaux, pilotados: a variação contínua pertence ao presente, ao acontecimento, é seguida, precipitada ou intersectada livremente. É uma filosofia do encontro, um teatro do encontro. Procede por imanência, por relações de horizontalidade, abandonando o domínio vertical da transcendência: deixar de saltar para se atingir o céu, e começar a navegar livremente o espaço-tempo; deixar a árvore e a explicação que já contém cada questão e assim conseguir novos encontros, impossíveis dentro de um plano estrutural e estruturado. Para isto, é preciso partir do que já está instalado:

C[armelo]B[ene] disse de inicio que é estúpido interessar-se acerca do princípio ou do fim de qualquer coisa, dos pontos de origem ou de terminação. 0 que é interessante não é nunca a maneira como alguém começa ou acaba. 0 interessante é o meio, o que se passa no meio. Não é por acaso que a velocidade maior é (atingida) no meio. As pessoas sonham muitas vezes com começar ou recomeçar do zero; e também eles têm medo do sitio onde irão chegar, do seu ponto de ruina. Pensam em termos de futuro ou de passado, mas o passado e mesmo o futuro pertencem à história. (Ibid.: 95)

Segundo Bene, o tempo do seu teatro é Aeon, não é Cronos. Cronos é a estrutura, o deus implacável que devora os seus filhos com dentes de conhecimento, é o peso em cima dos ombros que nos empurra para o chão quanto mais tentamos olhar para cima. Aeon é a possibilidade infinita, é o tempo do potenciamento, o plano dos devires. É o movimento imanente que pode elaborar qualquer direcção, intentar qualquer cruzamento. Estabelece linhas múltiplas que, não concorrendo para unificar o todo, verdadeiramente o potencializa. Aeon é passado, presente e futuro, é uma espécie de "sincronia diacrónica» que permite que tempos diferentes e acontecimentos de ordens 


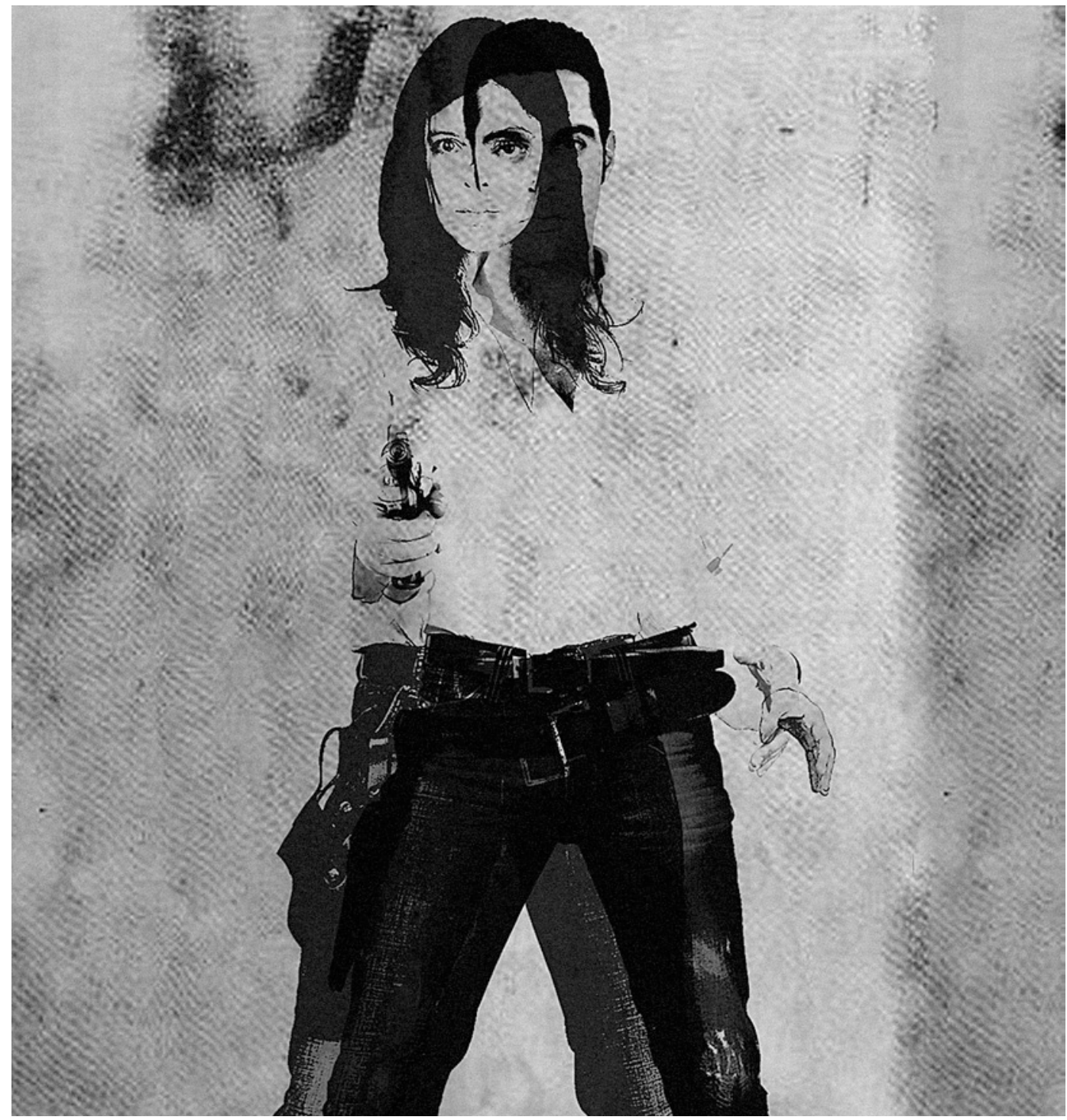

Han Shot First,

de Diogo Bento

Et Inês Vaz, 2010

(Inês Vaz e Diogo Bento)

fot. Alipio Padilha.

diferentes se possam encontrar para dai se extrairem novas sinteses. Bene opera, pilota este espaço-tempo, e faz comunicar os tempos, os signos, as paisagens, partindo sempre do meio, do instalado, de maneira a arrancar-lhe aquilo que não é da História, mas do ser, que não pertence mais ao sentido, mas que advém pela sensação. Para isso também o sujeito deve desaparecer: o teatro de Bene é um teatro que caminhará para o nascimento do sujeito, mas que, como não o representa, actua, ou actualiza-se, por devires, por potenciações, sustenta-se em velocidades, em sensações. Não há bem e mal, não há conflito, e por isso também não pode haver diálogo. 0 que há são vozes, "simultâneas ou sucessivas, sobrepostas ou transpostas, tomadas nessa continuidade espacio-temporal da variação, uma espécie de Sprechgesang" (Ibid.: 105). Carmelo Bene mune-se de uma imensa parafernália precisamente para atingir as diferentes modulações, projecções, amplificações e velocidades das vozes. Brincar aos significantes, construir novos planos de comunicabilidade, trabalhar a partir das possibilidades acústicas, pilotar o instrumento primário da comunicação humana que é a voz: no fundo, o mesmo desejo de Artaud, que não viveu para aceder às máquinas sonoras e visuais com que Carmelo Bene desenvolveu a sua experimentação teatral. Neste sentido:
0 homem de teatro não é mais autor, actor ou encenador. É um operador. Por operação, devemos entender o movimento de subtracção, de amputação, mas já coberto por outro movimento, que faz nascer e proliferar qualquer coisa de inesperado, como uma prótese... (Ibid: 89

A operação de menoração passa pelo fragmentar, pelo desterritorializar, ou destemporalizar, de uma dada potência e impor-Ihe (input) novas velocidades.

Essa função anti-representativa, será de indicar, de constituir de alguma forma uma figura da consciência minoritária, como potencialidade de qualquer um. Restituir uma potencialidade presente, actual, é uma coisa completamente diferente de representar um conflito. (Ibid: 125)

Os conflitos existem em espelho com a sua resolução, nunca se afastam do representável, do reconhecido, se forem vistos a partir de uma distância suficiente. Para restituir essas "potencialidades presentes", ou virtualidades inesperadas, há que reduzir, menorar. Bene afirmava que não fazia "teatro espectáculo", mas "sim teatro experimentação". Poderia ser chamado também teatroexploração. 


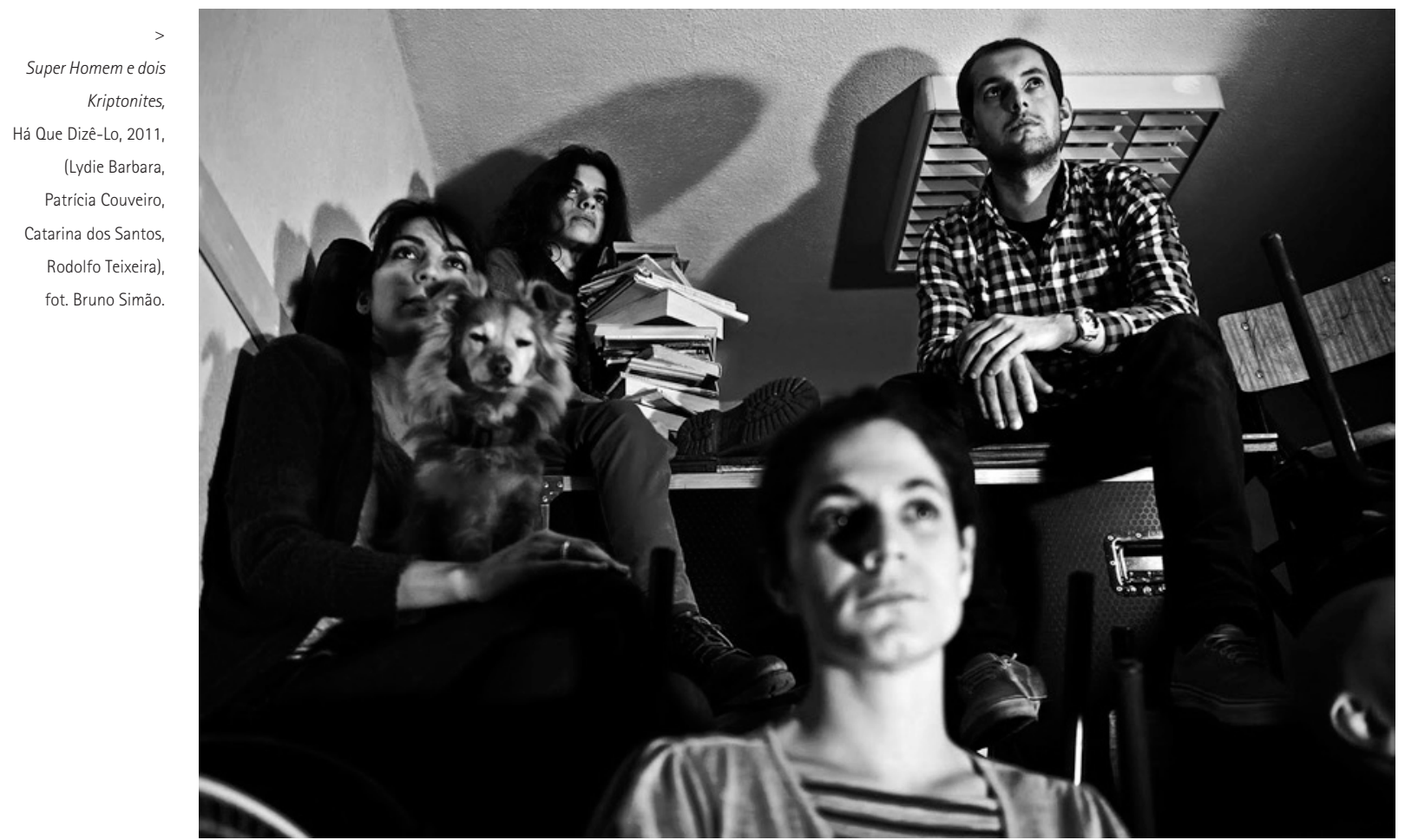

Quando ele escolhe amputar os elementos de poder, não é apenas a matéria teatral que muda, é também a forma do teatro, que deixa de ser "representação", ao mesmo tempo que o actor deixa de ser actor. (Ibid.: 93)

0 actor, o intérprete, seria antes considerado mero leitor de mapas. Quando o actor deixa de ser actor para se tornar operador, agenciador, assume o lugar de explorador: o que interessa não é elaborar um mapa novo mas sim percorrer o caminho, devir caminho.

Representar, para Deleuze, não será mais a função teatral por excelência: é uma causa perdida insistir nela, é apostar no absoluto definhamento da arte. 0 teatro deverá deixar de ser representatividade para se tornar movimento, variação contínua de infinitas possibilidades de pilotagem. Deverá situar-se mais próximo da música e da pintura, proceder por traços, não por formas. É esta a sua conclusão em Um manifesto a menos:

0 teatro surgirá como aquele que não representa nada, mas que apresenta e constitui uma consciência de menoridade, como deviruniversal, que opera alianças aqui ou ali consoante o caso, segundo linhas de transformação que saltam fora do teatro e tomam uma outra forma, ou que se reconvertem em teatro para um novo salto. É de facto uma tomada de consciência, que nada tem a ver com uma consciência psicanalítica, nem mais com uma consciência política marxista ou brechtiana. A consciência, a tomada de consciência é uma grande força, mas não é feita de soluções ou de interpretações. É quando a consciência abandona as soluções e as interpretações que ela conquista a sua luz, os seus gestos e os seus sons, a sua transformação decisiva. (Ibid.: 130)

Este projecto de teatro bene-deleuziano encontra hoje sólidas correspondências no panorama performativo português. A menoração enquanto "técnica" teatral, mais ou menos consciente, está presente no trabalho de criadores com uma carreira relativamente longa, como é o exemplo de Mónica Calle ou do Teatro Praga, mas também numa nova vaga de criadores como a dupla Diogo Bento \&t Inês Vaz, os Há Que Dizê-lo ou a Organização. Em comum, todos eles têm o facto de partirem de pressupostos fixos num determinado universo, que são movidos para outros planos, sendo recartografados. Han Shot First, primeiro espectáculo de Diogo Bento \&t Inês Vaz, é um espectáculo sobre começos, parte de uma pequena cena de Star Wars, e excede-a, constrói-Ihe um novo território, fazendo surgir potencialidades escondidas. Este pressuposto está também, apesar de diferenças estéticas consideráveis, bastante presente nos trabalhos dos Há Que Dizê-lo (exemplo de Super Homem e dois Kriptonites, onde elaboram uma performance a partir do espólio que recolheram de um palacete) ou da Organização, cujos espectáculos de estreia formam um ciclo que percorre a obra de Orwell através de pequenissimos blocos que se agenciam sonoramente.

Parece-nos, portanto, que aquilo que foi o laboratório de pensamento estético de Gilles Deleuze e Carmelo Bene representa hoje uma base de entendimento na procura artística do trabalho cénico dos novos criadores, mesmo que o possam fazer de forma inconsciente ou indirecta.

\section{Referências bibliográficas}

ARTAUD, Antonin (2006), 0 teatro e o seu duplo, trad. Fiama Hasse Pais Brandão, Lisboa, Fenda (Le théâtre et son double, Éditions Gallimard, Paris, 1966)

BENE, Carmelo / DELEUZE, Gilles (1979), Superpositions, Paris, Les Éditions de Minuit.

DELEUZE, Gilles / GUATTARI, Félix (2004), Rizoma, trad. Rafael Godinho, Lisboa, Assirio e Alvim (Rhizome, Paris, Les Éditions de Minuit, 1976). DELEUZE, Gilles (2000), Diferença e repetição, trad. Luiz Orlandi e Roberto Machado, Relógio d'Água, Lisboa (Différence et répétition, Paris, Presses Universitaires de France, Paris, 1968). 